\title{
The study of restoring an eco-habitat of the traditional Paiwan tribe in Taiwan
}

\author{
C.-J. Chen \\ Graduate Institute of Urban Development and Architecture, \\ National University of Kaohsiung, Taiwan, the Republic of China
}

\begin{abstract}
Paiwan is the third largest aboriginal tribe in Taiwan. The most particular, original habitat of Paiwan people is their housing system; all structures are constructed with numerous slats of stone and are built at the same altitude on mountains, merging with landscape. This type of vernacular architecture represents strongly, affordable resources and a kind of natural attitude that responds well with the environmental conditions. Using the local materials, applying the natural cooling and the landscape adaptation, and forming a selfsufficient community, the Paiwan habitat behaves as an eco-habitat and reflects the subtropical characteristic of Southern Taiwan.

Unfortunately, most of the traditional Paiwan territories are decomposed or abandoned due to political reason as well as the changing society during vicissitudinary periods in Taiwan. The government has urged the people to recover or restore the surviving villages. This study's purpose is to discuss how to find an appropriate approach for restoring the Old Chi-Jia village, one of the most complete and intact traditional Paiwan villages in Taiwan. Different topics such as the investigation process, the architectural intervention and community conservation are discussed to establish an optimal strategy for restoring the Old Chi-Chia village.

Keywords: aboriginal tribe, restoration, Paiwan, eco-habitation, Old Chi-Chia.
\end{abstract}

\section{Introduction and history}

The evidence found for prehistoric human habitation in Taiwan dates back 12,000 to 15,000 years. Different theories indicated that Taiwan's aborigines came from two places: southern China and Austronesia. Recent research shows 
that Taiwan could be the starting point of the Austronesian emigration route (Bellwood), i.e. Taiwan's aborigine people are an important branch of Austronesian. The Austronesians in Taiwan include two main groups: the plains aborigines and the mountain aborigines. The plains aborigines (called Pinpu tribe) resided mainly in the plain and coastal regions of Taiwan. Han people (Chinese) since the Dutch period came and have assimilated the plains aborigines in 1624. Until now, the plains aborigines could not be obviously identified.

Taiwan's aborigines are considered the northernmost Austronesian people. Among them, the official classification divides them into 12 major mountain tribes and 10 Pingpu groups. Mountain aborigines use the "tribe" as their settlement unit.

Those in the north (Atayal and Saisiat) live in scattered villages, those in central and southern Taiwan (Paiwan, Ami, Tsou) in compact communities, and the settlements for Bunun and Lanyu-based island (Yami) have the combination of the above features. Their houses are usually made of bamboo-wood columns covered with thatch. The Paiwan, Rukai and Bunun roof their buildings with stone slate and wood and often build their homes slightly underground. The Paiwan, closely related in material culture to the Rukai, are divided into the Raval and Vutsaul peoples. The Vutsul can be further subdivided into the Paumaumaq, Chaobobol, Parilarilao, and Pagarogaro groups. The tribe of Old Chi-Jia belongs to Paumaumaq.

\section{Concept of original habitation}

\subsection{Site environment}

The original settlement of the Paiwan tribe was usually situated on the contour of mountains. The altitude of settlement was around 500 to 1000 meters, where the relative mild climate provided both rich hunting resources as well as fertile soil. The houses of village were built close to linearly along the contour; all openings were in the same orientation. Every house unit had its independent territory: space, granary and courtyard, forming a self-sufficient habitat system. The traditional houses of the Paiwan and Rukai are similar to those of the Bunun. A site was levelled by digging into a slope, and then an earth and stone terrace that extended outward to provide a slightly lower than ground level floor and a slightly higher courtyard was revealed. Houses of the southern and eastern Paiwan, however, were frequently constructed at ground level.

The Old Chi-Jia village orients in a southwest direction, with the mountain background in a northeast direction that brings in the air stream from the Taiwan Strait into the village in summer and deters the cold current in winter (see Figures 1 and 2). All houses are built on the terraced field of contour. The pilled stone slates are around the two sides and the backside of the house, which protect and indicate every living unit. Some "Chief Houses" have a pilled stone platform in front of courtyard as a symbol of importance, which protects against wind. All grounds (inside and outside) are manually consolidated or covered with stone 
slates. In this manner, the house disturbs minimally the ground and thus performs a high permeability (see Figure 3).

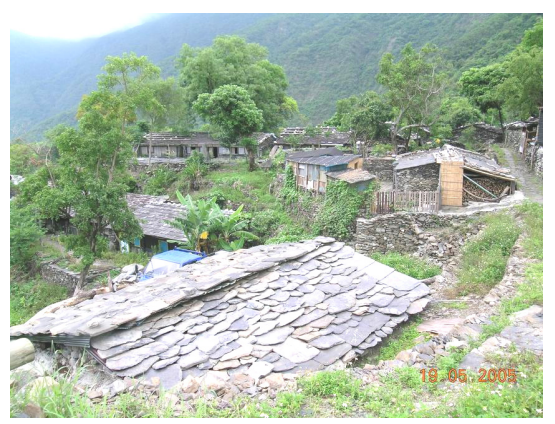

Figure 1: View of Old Chi-Jia village. Figure 2: $\quad$ Site map of Old Chi-Jia village (2005).

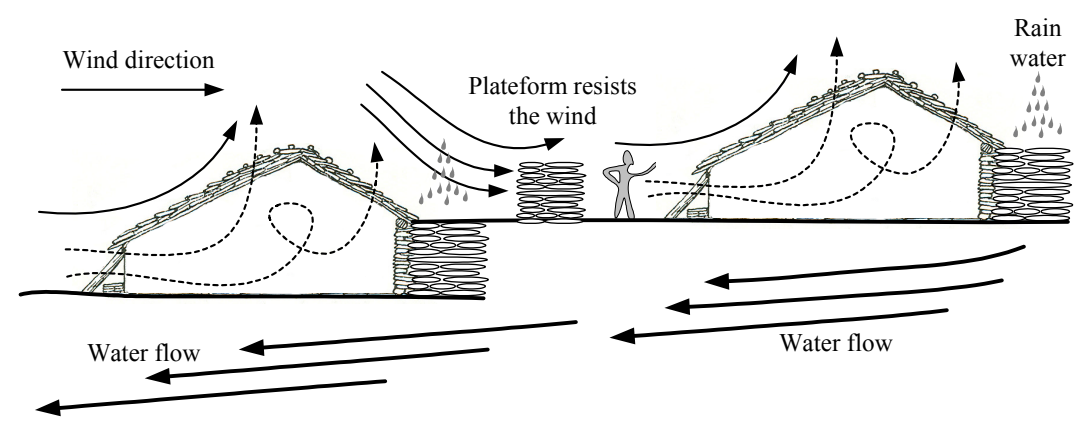

Figure 3: $\quad$ A profile of traditional houses of northern Paiwan tribe.

\subsection{Housing system}

The most particular feature of north Paiwan houses is its use of stone slate, which abounds in the mountains of southern Taiwan. Figure 4 describes a typical Rukai house in Pington County, and Figure 5 shows a typical Paiwan "Chief House" in Pington county. People use stone slate to build houses that are cool in the summer, warm in the winter and robust enough to resist typhoons. In other words, a structure entirely suited to the climate of southern Taiwan. Many traditional houses, which were erected more than one century ago, remain intact in southern Taiwan. Figure 6 is a traditional Northern Paiwan house that survived. Besides, the Paiwan and Rukai are famous for their outstanding wood and stone sculpture. Ancestral figures were often carved in shallow relief into house posts, slates, or plank panels. Figure 7 shows carving on wood planks. 

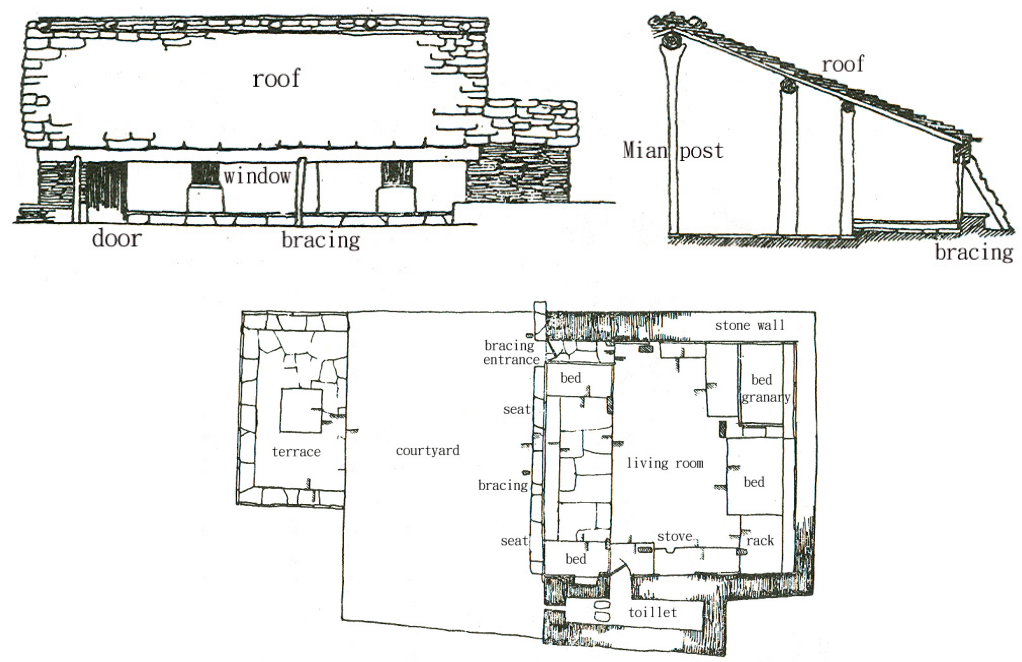

Figure 4: Typical Rukai House in Pington County (referred from original figures of Chijiiwa Suketarou).
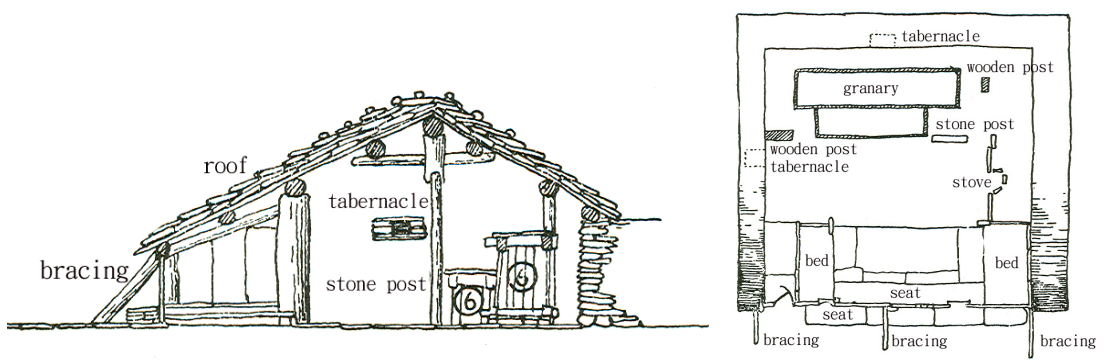

Figure 5: A typical Paiwan "Chief House" in Pington county (referred from original figures of Chijiiwa Suketarou).
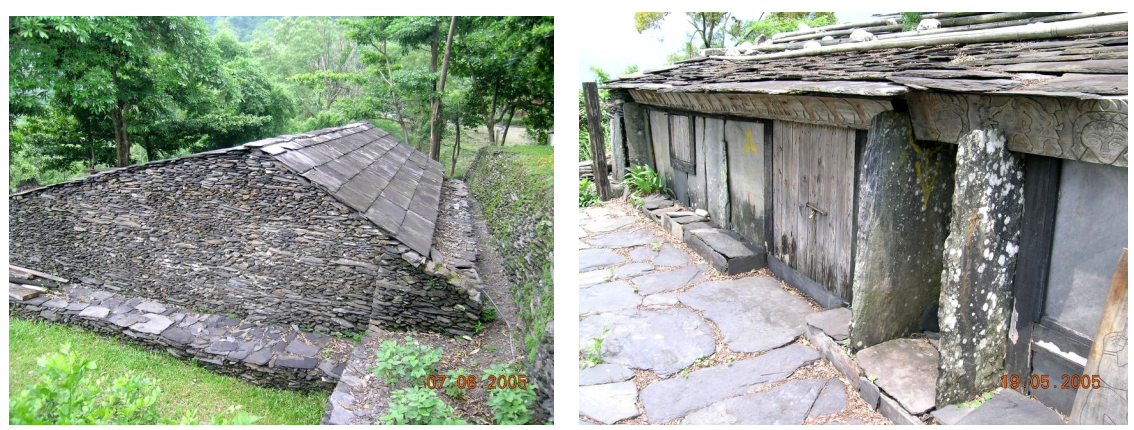

Figure 6: Side view of typical Paiwan Figure 7: Carved planks on front walls. House. 


\section{Menaces and challenges of the Paiwan tribe}

Although the government encourage various affirmative actions to assure the aboriginal peoples in Taiwan, the menaces and challenges are still inevitable. They are assumed as follows:

(1) Disadvantaged social position

(2) Inappropriate housing quality

(3) Vanishing traditional settlement

The Paiwan people as other minorities usually compete vigorously in most domains when they try to merge into a "normal" society. Despite limited agricultural products, the local people still mainly depend on the housing benefit and different income supports from government. The offered modern housing system seems to satisfy only the minimum requirements for living, all inherent respects and indigenous contents cannot be recognized. Moreover, the living quality, such as natural comfort and environmental atmosphere, is also incomparable to the traditional ones. Consequently, the young people leave their native land to chase or to accept "new values"; the traditional culture and the traditional settlement can hardly be inherited and are under danger of decomposition.

\section{Important criteria of renovation}

According to previous observations, this renovation project will face some critical situations. Two important objects are considered: (1) the preservation of living culture and (2) the possibility of renewable development. Three missions should be defined:

(1) Traditional respect in space - typology of house

(2) Enhanced living quality - improvement on comfort

(3) Preservation of materials and construction techniques

Figure 8 shows how the modernized Paiwan houses change the living aspects. When village people try to interpret the modernity and to become more "civilized", not only does the totem of the tribe disappear, but also the principal respects, such as social ethic and ancestral. In fact, continuous usage of the homes by future generations should be the most important philosophy when restoring these houses. And the correct reuse of houses could empower the new developments (eco-tourism, open-air cultural museum, etc.) for the tribe.

The authentication of the house should consist of both the appearance and traditional materials and construction techniques. Figure 9 shows the comparison of hand cut and machined stone slates. The quality of stone slate as well as traditional constructors is also critical.

For this project, local people are urged to participate in the construction for two reasons. The first is to offer more working possibilities to the tribe; the second is to train and to pass on their traditional techniques in an informal 
manner to those are willing to learn. A community participation action and several workshops will be held before and during the project.
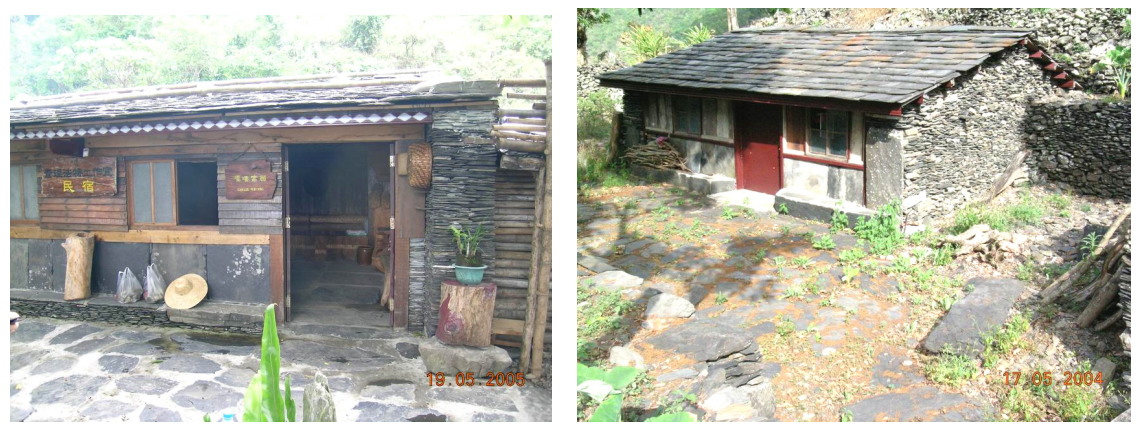

Figure 8: $\quad$ Modernized Paiwan houses in Old Chi-Jia Village.
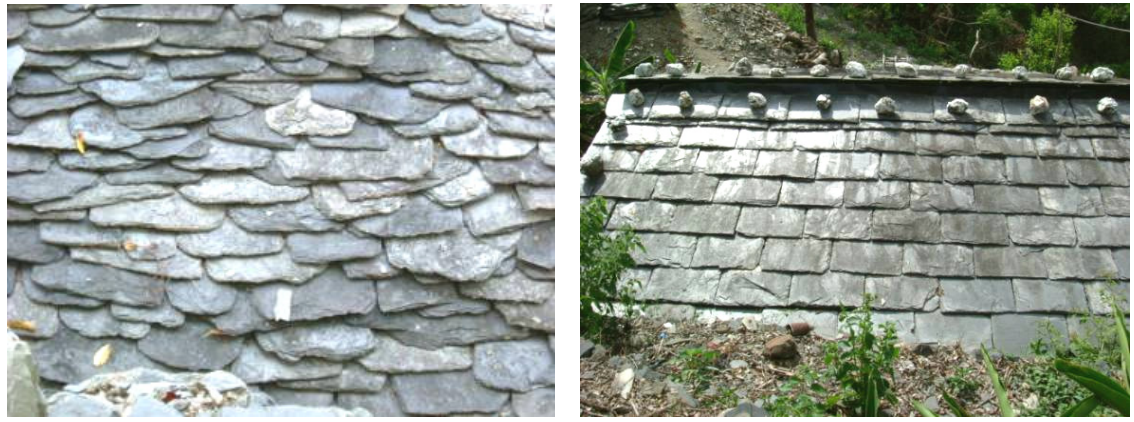

Figure 9: Comparison of hand cut (left) and machined (right) stone slates.

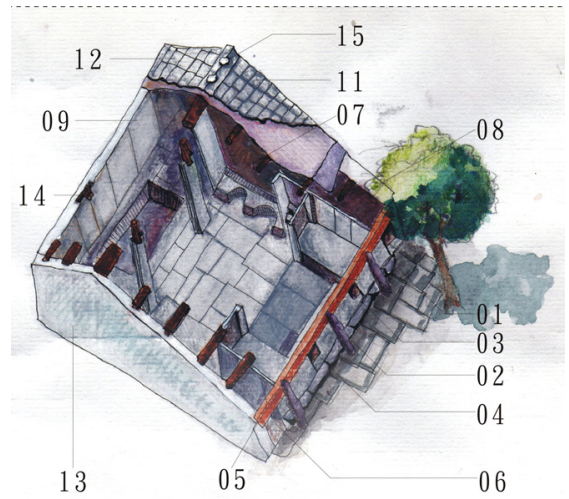

Figure 10: Typical feature of Paiwan House. 
To respect the traditional construction manner, a typical feature of traditional house is defined (see Figure 10). Table 2 shows the main components and its traditional names in Paiwan.

Table 1: $\quad$ Original names in Paiwan.

\begin{tabular}{|c|c|c|c|c|c|}
\hline No. & Name & Paiwan & No. & Name & Paiwan \\
\hline 01 & Courtyard & katsasavan & 09 & back wall & tsaiqus tseleb \\
\hline 02 & Bracing & qeoze & 10 & roof & vali \\
\hline 03 & front wall & tseleb & 11 & front roof & tsaiqaiau qaliu \\
\hline 04 & Window & quzong & 12 & back roof & tsaikuz qaliu \\
\hline 05 & plank panel & sasuaian & 13 & side wall & tsaikiti tseleb \\
\hline 06 & Door & paling & 14 & tabernacle & tavi \\
\hline 07 & main post & taukes & 15 & stone & Mui \\
\hline 08 & Granary & sang & & & \\
\hline
\end{tabular}

\section{Architectural interventions}

\subsection{Restoration inventory}

In order to set up a feasible restoration plan, a fundamental inventory was necessary. The inventory list consists of materials to be used in different parts of the house, the damaged description (mentioned quantitatively and qualitatively), the principal plants around the house and the actual circumstance of every house. According to the classification of different damaged levels, the sequence of restoration for houses was defined.

Due to limited budget, the project focused on deciding the priority of recovering the houses that could be reused quickly and could be demonstrated as exemplary models for the county. Figure 11 shows an investigation sheet form and inventory list.

\subsection{Modified structural system}

Traditional houses are built with less durable materials except for the stone elements. Especially, the weight of a stone roof can be hardly supported because of the ageing of wood element (beams, rafters). Therefore, the safety of houses decreases gradually. In this project, the integrity structure of a house should be improved and refined, thus not only was the traditional structure reinforced or rebuilt, but also a modified structural system was proposed. Anti-termite treated wood material and more durable stone slates should replace the old ones respectively. 


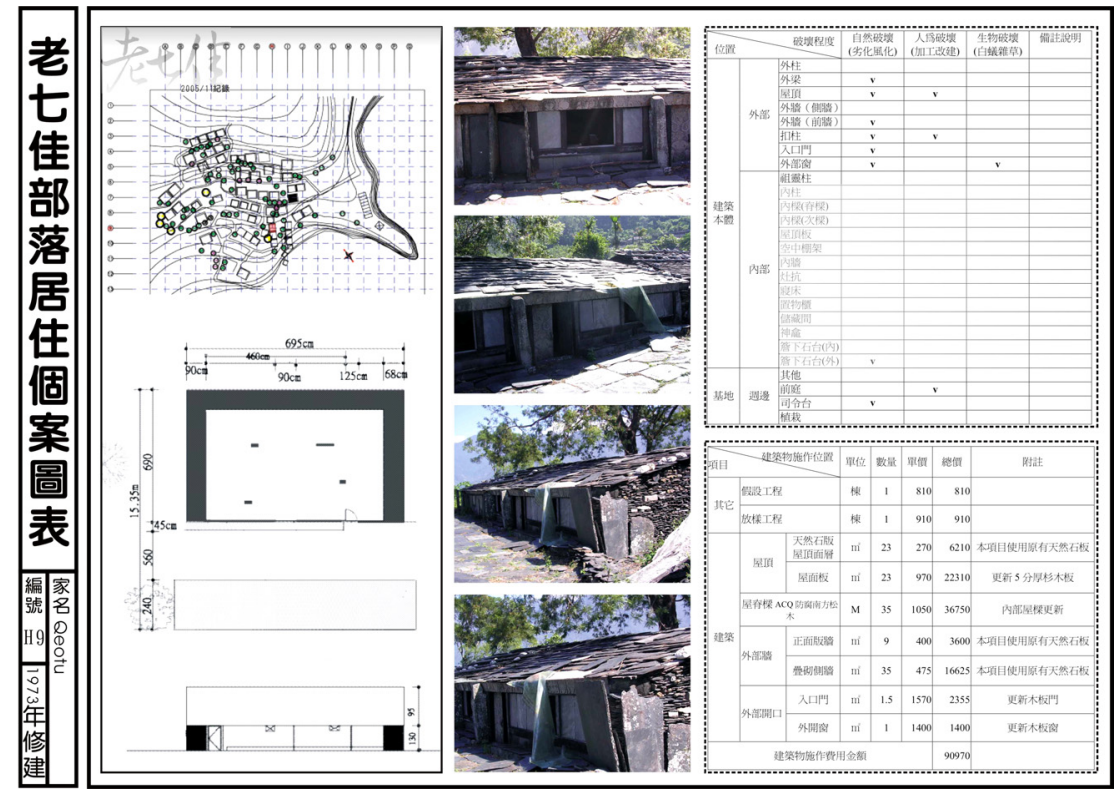

Figure 11: Investigation sheet form and inventory list.

Table 2: $\quad$ Indoor Environmental Factors (Data referred from Meng [3]).

\begin{tabular}{|c|c|c|c|c|c|c|c|c|c|}
\hline \multirow{3}{*}{$\begin{array}{c}\begin{array}{c}\text { Assessment } \\
\text { topics }\end{array} \\
\begin{array}{c}\text { Standard } \\
\text { values }\end{array}\end{array}$} & \multicolumn{2}{|c|}{$\begin{array}{c}\text { Indoor } \\
\text { Temperature }\left({ }^{\circ} \mathrm{C}\right)\end{array}$} & \multirow[t]{2}{*}{ PMV } & \multicolumn{2}{|c|}{ PPD } & \multicolumn{2}{|c|}{$\begin{array}{c}\mathrm{ACH} \\
(1 / h)\end{array}$} & \multicolumn{2}{|c|}{$\begin{array}{c}\mathrm{Q} \\
\left(\mathrm{m}^{3} / \mathrm{h} / \mathrm{m}^{2}\right)\end{array}$} \\
\hline & Winter & Summer & & Win. & Sum. & Win. & Sum. & Win. & Sum. \\
\hline & 20 24 & $23 \sim 26$ & $-1 \sim+1$ & $10 \%$ & $15 \%$ & $3 \sim 6$ & $3 \sim 6$ & 8 & 8 \\
\hline $\begin{array}{c}\text { Winter } \\
\text { (traditional) }\end{array}$ & 20.97 & & -0.33 & $8.42 \%$ & & 8.36 & 7.59 & 21.91 & 19.9 \\
\hline $\begin{array}{c}\text { Summer } \\
\text { (traditional) }\end{array}$ & & 24.93 & 0.59 & & $12.84 \%$ & 13.09 & 5.44 & 34.31 & 14.26 \\
\hline $\begin{array}{l}\text { Winter } \\
\text { (modern) }\end{array}$ & 21.13 & & -0.33 & $8.41 \%$ & & 5.91 & 1.05 & 6.08 & 0.55 \\
\hline $\begin{array}{l}\text { Summer } \\
\text { (modern) }\end{array}$ & & 29.1 & 1.28 & & $39.61 \%$ & 14.17 & 2.52 & 14.57 & 1.32 \\
\hline
\end{tabular}

\subsection{Improved ventilation}

Due to ethnic policy and natural disasters (mudflow, flood and earthquake), several migrations occurred prior to the actual habitation. Most of the people live 
in the modernized but inappropriate housing system. To discuss the comfort of Paiwan houses seems a little extravagant. Very few researches mentioned the physical states of such housing system. Meng [3] studied how the natural ventilation influences the indoor environment of the Northern Paiwan Tribe. The indoor Predicted Mean Vote (PMV), Predicted of Percentage Dissatisfied (PPD), Air change per hour $(\mathrm{ACH})$ and Air exchanged rate $(\mathrm{Q})$ are discussed. The measured results show that the traditional Paiwan houses perform better on $\mathrm{ACH}$ and $\mathrm{Q}$, which provide a superior indoor air quality compared to the modern ones. For PMV and PPD, the traditional ones also have the advantage of thermal comfort. The comparison results are shown in Table 2.

For traditional houses, the smoke from cooking and campfire can barely dissipate due to the inefficient ventilation. The stacked stonewalls and roof can lightly "respire" and can evacuate a small percentage of the smoke. But in modern houses, the stone slates are usually stacked and "sealed" by mortar.

It is necessary to propose a modified ventilation system (shown as Figure 12) that can be combined and built with main structural system. The indoor air quality of houses will be thus improved.
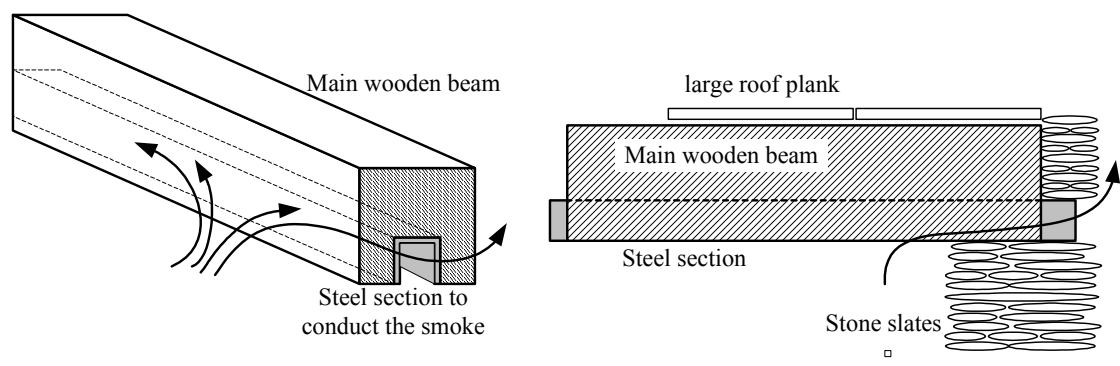

Figure 12: $\quad$ Ventilated steel section beneath the main wooden beam.

\section{Conclusion and perspective}

As a unique aboriginal habitation in southern Taiwan, the Old Chi-Jia village should have a chance to be a living heritage of Paiwan culture. The meaning of this restoring project is to preserve the authentic habitation and at the same time, to consider the future perspective of the tribe.

Comparing to the modern houses, the advantages of traditional houses on thermal comfort and on IAQ are clarified. Such wisdom and the ecological concept fund in vernacular habitation can always inspire us on how to harmonize the natural environment and resources with human settlement.

More aspects like anthropology and environment science should be introduced and integrated into such projects to resolve comprehensively the requirement of aboriginal tribes in Taiwan. 
82 Eco-Architecture: Harmonisation between Architecture and Nature

\section{References}

[1] P. Bellwood, J. Fox, and D. Tryon, eds., "Austronesian Prehistory in Southeast Asia: Homeland, Expansion and Transformation" The Austronesians. Pp. 96-111.1997

[2] Chijiiwa Suketarou, The Dwellings of Aborigines in Taiwan (in Japanese), 1960 Tokyo, 1988 Taipei.

[3] Hui-Tung Meng, The effects on the Environmental Changes by Natural Ventilation to the stone-plate Houses of Northern Pai-Wan Tribe (in Chinese), Master thesis, Shu-Te University of Technology, 2005.

[4] http://www.gio.gov.tw/taiwan-website/5-gp/yearbook/2004

[5] Moderate thermal environments-Determination of the PMV and PPD indicesand specification of the conditions for thermal comfort", International Standard ISO7730, 1994.

[6] Chi-Jen CHEN, Recovery Project for Stone Slate Houses of Old Chi-Jia Village, Technical Report, 2006. 